\title{
Diachronic Aspects of Preferred Argument Structure in English and Broader Implications ${ }^{1}$
}

\author{
REIJIROU SHIBASAKI \\ University of California, Santa Barbara
}

\section{Preferred Argument Structure: A Background History}

Du Bois (1987) derived the theory of Preferred Argument Structure from his research on the ergative language, Sacapultec Maya. Because of no unitary category of subject, Du Bois refers to Dixon (1979) who is one of the initiators of labels for each core argument: A for the subject of a transitive verb (or a two-argument verb), $\mathrm{S}$ for the subject of an intransitive verb (or a one-argument verb), and $\mathrm{O}$ for the direct object of a transitive verb (or a two-argument verb). The findings from the dissection of Sacapultec Maya by these labels are summarized in (1) (from Du Bois 1987:829). From here on, Preferred Argument Structure is abbreviated as PAS.

(1) Dimensions and Constraints of Preferred Argument Structure

\begin{tabular}{|c|l|l|}
\hline & \multicolumn{1}{|c|}{ Grammar } & \multicolumn{1}{c|}{ Pragmatics } \\
\hline Quantity & $\begin{array}{l}\text { One Lexical Argument } \\
\text { Constraint }\end{array}$ & $\begin{array}{l}\text { One New Argument } \\
\text { Constraint }\end{array}$ \\
\hline Role & Non-Lexical A Constraint & Given A Constraint \\
\hline
\end{tabular}

Du Bois argues that PAS consists of two dimensions: grammatical and pragmatic dimensions, as in (1). The grammatical dimension has two constraints. One is the 'one lexical argument constraint', which derives from the fact that in Sacapultec narratives, only a small number of clauses have more than two core arguments as lexical NPs. In other words, any additional core arguments tend to appear as pronominals or zero forms in this language. The other constraint is the 'non-lexical A constraint', which means that if there is a lexical NP in a clause, it

\footnotetext{
${ }^{1}$ I would like to thank Mira Ariel, Susanna Cumming, John W. Du Bois, Carol Genetti, Sandra A. Thompson, Akiyo Maruyama, Joseph Park, Makiko Takekuro, and Toshiko Yamaguchi for invaluable comments for the preparation of this paper. Also, I would like to sincerely thank Elizabeth Closs Traugott for her comments on this paper at the conference. Neediess to say, I am responsible for any remaining inconsistencies or mistakes.
} 
tends to appear in $\mathrm{S}$ or $\mathrm{O}$, but not in $\mathrm{A}$.

The pragmatic dimension also has a pair of constraints. One is the 'one new argument constraint' which is set out to explain a strong tendency that clauses tend not to contain more than one new argument. The 'given A constraint' is the other constraint to explicate that new arguments have a tendency to appear in $\mathrm{S}$ or $\mathrm{O}$, but not in A.

The arguments set forth by Du Bois (1987) have been attested in various languages accompanied with some cross-linguistic validity, but at times they have been challenged with some language-specific ${ }^{2}$ or genre-specific behaviors of each label ${ }^{3}$ in several languages. For example, it seems universally valid that $\mathrm{A}$ is strongly disfavored for encoding new information with a full lexical noun (e.g. see Kärkkäinen (1996) for English, Ashby \& Bentivoglio (1994) for French and Spanish, Matsumoto (2000) for Japanese, and Arnold (1998) for a cross-linguistic study including English, Spanish and Mapudungun). On the other hand, language-specific aspects of PAS have been claimed, especially with regard to the role of S. Du Bois (1987) suggests that $S$ and $O$ are considered to behave in the same way to introduce new information in Sacapultec. Herring (1989:126ff) finds, however, that $\mathrm{O}$ does not behave like $\mathrm{S}$ in Tamil; in other words, $\mathrm{S}$ patterns with $\mathrm{A}$ in two of her texts, while S patterns with O in the other in Tamil. Durie (1988) also says about PAS in Acehnese (North Sumatra, Austronesian) that "the most salient distinction is between Actors, which rarely code new mentions, and Undergoers, which often do" (p.19) and "97\% of new mentions are coded as Undergoers" (p.18). ${ }^{4}$

In addition to synchronic elaborations of PAS, some researchers have succeeded in uncovering the diachronic aspects of PAS. Building on their synchronic study in French and Spanish, for example, Ashby \& Bentivoglio (to appear) also discuss diachronic aspects of PAS in French and Spanish, with

\footnotetext{
${ }^{2}$ Several new findings from Nepali are illustrated in Genetti \& Crain (to appear). For example, inanimate referents are hard to be mentioned as pronominal, and pronouns never encode new information and are rarely, if ever, accessible or referential. See Du Bois, Kumpf, \& Ashby (to appear) for other new works on Preferred Argument Structure in various languages.

${ }^{3}$ For example, O'Dowd (1990:382-83) illustrates that in her English data from paramedical training sessions, $\mathrm{S}$ and $\mathrm{A}$ are found to contain consistently lower percentage of new information than $\mathrm{O}$ and OBL. Kumpf (1993) also claims that "... the characterization of introduction as predominantly in $S$ role is an artifact of the kind of data examined... namely Pear Story narratives" (cited in Kärkkäinen 1996:689). The $S$ role is considered to be sensitive to the difference in genre and changes in discourse, for which Du Bois (1987:836) invented the term 'Information Pressure'.

${ }^{4}$ Preferred Argument Structure seems to be influenced by morpho-syntactic structures or semantic behaviors of each label in a given language. Acehnese is a 'Split-S' language (see Dixon (1979)). Therefore, $S$ still indicates 'half-S' regardless of whether $S$ is split in meaning into Actors and Undergoers. I am grateful to Susanna Cumming for this comment. As to different behaviors of $S$ in her American conversational data from those in Sacapultec Maya in Du Bois (1987), Kärkkâinen (1996:697) attributes the difference to their morphological differences, saying that “... the two subject roles in English, $A$ and $S$ do not differ from each other morphologically, and both govern verb agreement in the same way".
} 
several new speculations on the development of PAS. Resonant with other synchronic accounts of PAS, Ashby \& Bentivoglio argue that $S$ is ambivalent about introducing new information across time, and that even intransitive subjects of copulas (Se, in their term) also strongly disfavor new referents across time. ${ }^{5}$

Building on speculations from preceding studies, this study aims to determine whether PAS holds for early stages of English. As Ashby \& Bentivoglio (to appear) concede in their concluding remarks, a simple comparison of PAS, in Old French and Modern French for example, is not sufficient for uncovering and understanding the nature of PAS. Therefore, this study aims to show the gradual transition of PAS in the history of English.

\section{Data}

For this study, the following texts, which may be considered to best reflect colloquial expressions of those times, are selected.

$\begin{array}{ll}\text { Stage and Text: } & \\ \text { Old English (OE): } & \text { The Battle of Maldon (c.991) } \\ \text { Middle English (ME): } & \text { The Canterbury Tales (c.1388-1400) } \\ \text { Early Modern English (EModE): } & \text { The Tempest (c.1612) } \\ \text { Present Day English (PDE): } & \text { Lady Windermere's Fan (c.1892) }\end{array}$

The Battle of Maldon is the last text of the series of epics from Beowulf. The important thing is that the first conversational part of this text (lines 29-4l) is considered to be 'the first literary use of dialect in English' (Robinson 1976:25-28). ${ }^{6}$ From The Canterbury Tales, I chose The Pardoner's Tale. Because this study focuses on the first 200 clauses from each text to avoid any biases (see section 2), a text was necessary which has as a lot of conversation at the beginning, hopefully of a speaker/narrator's commitment to the story. For this, The Pardoner's Tale was one of the best. The Tempest ${ }^{7}$ and Lady Windermere's Fan are both very popular plays of their respective periods. Moreover, the first

\footnotetext{
${ }^{5}$ In Ashby and Bentivoglio (to appear), there are many other new findings about the development of PAS. One of the most striking speculations concerns the 'pro-drop' phenomenon in Modern Spanish in terms of PAS (footnote 6). According to their analysis, A was already disfavored for the introduction of new information in Old French and Old Spanish (the ratios of lexical NPs in A are $26 \%$ and $16 \%$, respectively), and most As were zero forms ( $56 \%$ for Old French and $76 \%$ for Old Spanish). A pro-drop phenomenon in Old Spanish was more dominant than in Old French (the overall ratio of zero forms are $28 \%$ in Old French and $39 \%$ in Old Spanish). This finding enables them to argue that "this trend apparently continues, with the pronoun having become obligatory in Modern French, but not in Modern Spanish." If other stages between Old French/Spanish and Modern French/Spanish provide support for their analysis, this speculation would be further solidified and shed new light on the 'pro-drop' phenomenon in Old French. For other diachronic studies, see papers cited in Ashby \& Bentivoglio (to appear).

${ }^{6}$ Hiltunen (1997) suggests that it is possible to analyze The Battle of Maldon in terms of 'face' theory introduced by Goffman (1967).

${ }^{7}$ The Tempest may be different from the typical verse of Shakespeare's other plays. I am grateful to Elizabeth Closs Traugott for this comment.
} 
parts of them are full of interaction by characters.

\section{Methodology}

For this study, I coded for four properties. First, the first 200 clauses are selected from each text to avoid any biases. Second, four categories are used for this study: $\mathrm{A}, \mathrm{S}, \mathrm{O}$ and Oblique. I will follow the basic definitions of $\mathrm{A}, \mathrm{S}$, and $\mathrm{O}$ given in the introduction. The definition of Oblique (hereafter, OBL) is an object of a preposition (see Thompson (1997) for the role of OBL in discourse).

The third coding property is the recency of mention of any lexical nouns and pronouns. There are several notions, terms and definitions relating to recency of mention (see Chapter 2 of Arnold (1998) for details). I shall use the terms, 'Old', 'Active', and 'New', and define them as follows: Old=had appeared in text previously, but not in the immediately previous clause; Active=appeared in the immediately previous clause; New=brand new to the text.

The fourth coding property relates to forms of reference. They are Null, Pronoun, and Lexical Noun (Null=zero forms (see below); Pronouns (hereafter, Pron) $=$ they, her, him, it, ...etc.; Lexical (hereafter, Lex) $=$ hawk, messenger, Byrhtnoth, ...etc.). Null forms are marked $\emptyset$ in my examples, which means that a certain argument which is considered to be called for by the predicate's argument structure is not realized in the clause. These coding properties are illustrated in (3). Note that each category, A, S, O, and OBL are all underlined.

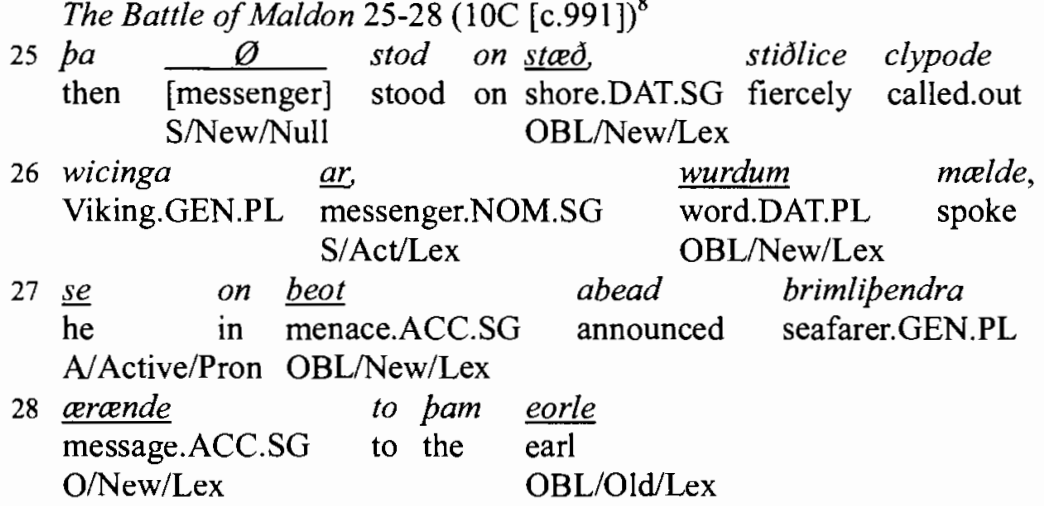

'Then [Ø (messenger)] appeared on the opposite bank, a messenger of the Vikings called out fiercely, spoke in words, he threateningly delivered the Vikings' message to the earl (Byrhtnoth)...'

Two lines are added for each line of the original text. The italicized line is the original text, while the second and third lines are allotted for glossing and coding

${ }^{8}$ The glossing conventions are as follows: $\mathrm{ACC}=$ accusative; $\mathrm{DAT}=$ dative; GEN=genitive; NOM=nominative; $\mathrm{PL}=$ plural; $\mathrm{SG}=$ singular. 
properties for PAS, respectively. The marker $\emptyset$ in line 25 indicates that there is no syntactic argument in the slot, although it is called for by the argument structure of moelde 'spoke'. Abbreviated forms like S/Act/Lex in line 26 indicate, for example, that the word ar 'messenger' is regarded as S (= subject of an intransitive (or one-argument) verb, malde 'spoke'), pragmatically Active (= appeared in the immediately previous clause, that is, $\varnothing[=$ messenger $]$ ), and syntactically Lexical, not Pronoun or Null. Because of limitations of space, I will omit other examples.

\section{Results}

The analysis of the data yields several interesting findings about the diachrony of PAS in English. Some of them give support for Du Bois (1987) and other previous studies, while some seem to be new findings about PAS. Because of limitations of space, I will mainly focus on the proportional frequencies of lexical vs. pronominal mentions of each category, that is, A, S, O, and OBL over history.

\subsection{Diachronic Aspects of $A$ in English}

The following are the findings about $\mathrm{A}$. As explained in section $0, \mathrm{~A}$ is strongly disfavored cross-linguistically for encoding new information with a full lexical noun. The result of this analysis also strengthens this cross- linguistic generalization from a diachronic perspective.

(4) Findings about $\mathrm{A}$ based on 4 selected texts

a. A has come to be disfavored for encoding (New/)Lex over history.

b. Pronouns are strongly favored for $\mathrm{A}$.

c. The previous clause is the preferable place for the last mention over history. ${ }^{9}$

(5) Proportional Frequency of Pronominal vs. Lexical Mentions in A

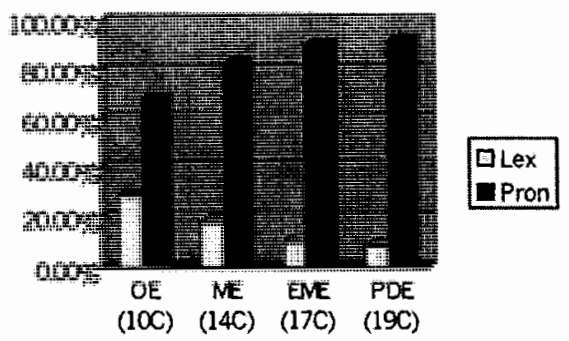

${ }^{9}$ In OE through PDE, the most preferable position of reference for pronouns is the immediately previous clause (= Active, in this study). The ratios of Active over Old and New are: $74.2 \%(\mathrm{OE})$, $64.8 \%$ (ME), 60.3\% (EModE), 68.8\% (PDE). Cf. Givon (1983). The reason why Active is most pervasive in OE may be attributive to 'variation', a kind of appositional construction in OE verse. 
Ashby \& Bentivoglio (to appear) argue that A was already disfavored for new referents in Old French and Old Spanish (the ratios of lexical NPs in A are 26\% and $16 \%$, respectively; see footnote 5 for details). In OE, A behaves in the same way as in Old French (the ratio is $27.5 \%$ ). Importantly, my data suggest that the proportional frequency of lexical nouns has gradually decreased over history, whereas that of pronouns has increased, as illustrated in (5) and (6a-d). This diachronic transition of information status in A supports the two constraints in (1): 'Non-Lexical A Constraint/Given A Constraint', with an implication that A strongly disfavors introducing new information beyond the realms of morpho-syntactic structures of ergative or accusative languages.

(a) $\mathrm{A}$ in $\mathrm{OE}(10 \mathrm{C})$

\begin{tabular}{|c|c|c|c|c|}
\hline & Null & Pron & Lex & Total \\
\hline Old & 2 & 6 & 4 & 12 \\
\hline Active & 1 & 44 & 4 & 49 \\
\hline New & 0 & 2 & 14 & 16 \\
\hline Total & 3 & 52 & 22 & 77 \\
\hline
\end{tabular}

(b) $\mathrm{A}$ in $\mathrm{ME}(14 \mathrm{C})$

\begin{tabular}{|c|c|c|c|c|}
\hline & Null & Pron & Lex & Total \\
\hline Old & 0 & 18 & 4 & 22 \\
\hline Active & 0 & 50 & 2 & 52 \\
\hline New & 0 & 6 & 10 & 16 \\
\hline Total & 0 & 74 & 16 & 90 \\
\hline
\end{tabular}

(b) A in EModE (17C)

\begin{tabular}{|c|c|c|c|c|}
\hline & Null & Pron & Lex & Total \\
\hline Old & 0 & 10 & 2 & 12 \\
\hline Active & 0 & 36 & 0 & 36 \\
\hline New & 0 & 8 & 4 & 12 \\
\hline Total & 0 & 54 & 6 & 60 \\
\hline
\end{tabular}

(c) $\mathrm{A}$ in $\mathrm{PDE}(19 \mathrm{C})$

\begin{tabular}{|c|c|c|c|c|}
\hline & Null & Pron & Lex & Total \\
\hline Old & 0 & 32 & 0 & 32 \\
\hline Active & 0 & 56 & 2 & 58 \\
\hline New & 0 & 2 & 6 & 8 \\
\hline Total & 0 & 90 & 8 & 98 \\
\hline
\end{tabular}

\subsection{Diachronic Aspects of $S$ in English}

The findings about $\mathrm{S}$ tell us about the ambivalent status of introducing new referents from a diachronic perspective. As pointed out in Kärkkäinen (1996), S in her American English conversational discourse tends to pattern with A rather than $\mathrm{O}$, though she notes that "... S is flexible and reacts to the changing discourse conditions more readily than $A$ " (p.688). The texts used for this study are all written in British English, not in American English. Therefore, it may not be appropriate to simply compare the results of Kärkkäinen (1996) and those of this study; however, it seems possible to show how the $S$ role has come to behave in PDE. In fact, the findings from Kärkkäinen (1996) relate well to those of this study (see below). The following are the diachronic findings of aspects of PAS in English. Note that the copula's complement (S-Comp) is included in S. 


\section{Diachronic Aspects of Preferred Argument Structure}

(7) Findings about $\mathrm{S}$ based on 4 selected texts

a. (Active/)Pron and (New/)Lex were competing in OE and ME.

b. After ME, (New/)Lex began to decrease, while (Act/)Pron became dominant in PDE.

c. But still, $\mathrm{S}$ behaves differently from $\mathrm{A}$.

(8) Proportional Frequency of Pronominal vs. Lexical Mentions in S

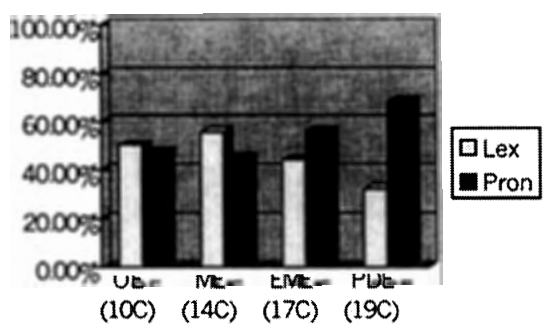

According to Ashby \& Bentivoglio (to appear), S has been ambivalent about introducing new referents in Old/Modern French and Spanish. The findings from $\mathrm{OE}$ and ME support their finding about $\mathrm{S}$. However, the ratio of introducing new referents in $\mathrm{S}$ began to decrease after $\mathrm{ME}$ on, as in (8) above, which goes against the diachronic findings for PAS in French and Spanish. It is true that the results from this study may not go beyond the realms of case study; however, the ratios of lexical nouns over pronouns have consistently become lower from ME through PDE.

(a) $\mathrm{S}$ in $\mathrm{OE}(10 \mathrm{C})$

\begin{tabular}{|c|c|c|c|c|}
\hline & Null & Pron & Lex & Total \\
\hline Old & 0 & 2 & 8 & 10 \\
\hline Active & 2 & 30 & 12 & 44 \\
\hline New & 0 & 0 & 14 & 14 \\
\hline Total & 2 & 32 & 34 & 68 \\
\hline
\end{tabular}

(c) $\mathrm{S}$ in EModE (17C)

\begin{tabular}{|c|c|c|c|c|}
\hline & Null & Pron & Lex & Total \\
\hline Old & 0 & 8 & 4 & 12 \\
\hline Active & 0 & 30 & 0 & 30 \\
\hline New & 0 & 8 & 32 & 40 \\
\hline Total & 0 & 46 & 36 & 82 \\
\hline
\end{tabular}

(b) $S$ in ME (14C)

\begin{tabular}{|c|c|c|c|c|}
\hline & Null & Pron & Lex & Total \\
\hline Old & 0 & 12 & 8 & 20 \\
\hline Active & 0 & 30 & 0 & 30 \\
\hline New & 0 & 6 & 52 & 58 \\
\hline Total & 0 & 48 & 60 & 108 \\
\hline
\end{tabular}

(d) $\mathrm{S}$ in PDE (19C)

\begin{tabular}{|c|c|c|c|c|}
\hline & Null & Pron & Lex & Total \\
\hline Old & 0 & 18 & 2 & 20 \\
\hline Active & 0 & 64 & 8 & 72 \\
\hline New & 0 & 18 & 38 & 56 \\
\hline Total & 0 & 100 & 48 & 148 \\
\hline
\end{tabular}

Importantly, the low frequency of lexical nouns in S from ME through PDE 
can lead to Kärkkäinen's (1996) finding that S behaves like A in two of her three texts in American conversational discourse. This fact deserves consideration. $\mathrm{S}$ is sensitive to the difference in genre and changes in discourse in the sense of 'Information Pressure' (Du Bois 1987:836), as is often suggested in various studies (see note 3 and 4). In my opinion, however, S also seems to have changed its role, at least in the English texts I looked at, from favoring new referents to disfavoring them over time. This speculation needs further research, but the findings from this study support this view, as is summarized in (8) and (9a-d).

\subsection{Diachronic Aspects of $O$ in English}

The findings about $\mathrm{O}$ are intriguing both diachronically and typologically. For example, Ashby \& Bentivoglio (to appear) argue that $\mathrm{O}$ favors the introduction of new information in both Old and Modern French and Spanish. Likewise, synchronically, many studies reach a consensus on the skewed behavior of $\mathrm{O}$ introducing new information. However, the result of this study casts doubt on this almost unanimous view, as follows.

(10) Findings about $\mathrm{O}$ based on 4 selected texts

a. In $\mathrm{OE}$ through EModE, $\mathrm{O}$ was preferred for the introduction of (New/)Lex.

b. In PDE, O came to prefer (Act/)Pron to (New/)Lex.

As in (11), the proportional frequency of lexical nouns over pronouns has gradually but steadily decreased across time, and then reversed in PDE. It is attested in various languages that $O$ strongly prefers new information to old/given information; however, it seems that the reversed situation has not yet been reported either typologically or diachronically.

(11) Proportional Frequency of Pronominal vs. Lexical Mentions in O

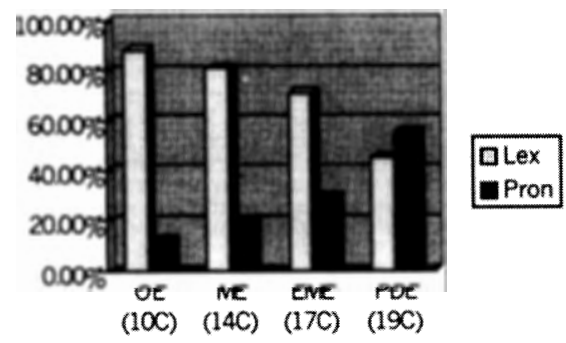


(12)

(a) $\mathrm{O}$ in $\mathrm{OE}(10 \mathrm{C})$

\begin{tabular}{|c|c|c|c|c|}
\hline & Null & Pron & Lex & Total \\
\hline Old & 0 & 2 & 14 & 16 \\
\hline Active & 1 & 6 & 24 & 31 \\
\hline New & 0 & 8 & 80 & 88 \\
\hline Total & 1 & 16 & 118 & 135 \\
\hline
\end{tabular}

(c) O in EModE (17C)

\begin{tabular}{|c|c|c|c|c|}
\hline & Null & Pron & Lex & Total \\
\hline Old & 0 & 6 & 6 & 12 \\
\hline Active & 0 & 16 & 0 & 16 \\
\hline New & 0 & 10 & 72 & 82 \\
\hline Total & 0 & 32 & 78 & 110 \\
\hline
\end{tabular}

(b) $\mathrm{O}$ in $\mathrm{ME}(14 \mathrm{C})$

\begin{tabular}{|c|c|c|c|c|}
\hline & Null & Pron & Lex & Total \\
\hline Old & 0 & 6 & 4 & 10 \\
\hline Active & 0 & 14 & 2 & 16 \\
\hline New & 0 & 2 & 88 & 90 \\
\hline Total & 0 & 22 & 94 & 116 \\
\hline
\end{tabular}

(d) $\mathrm{O}$ in PDE (19C)

\begin{tabular}{|c|c|c|c|c|}
\hline & Null & Pron & Lex & Total \\
\hline Old & 0 & 6 & 6 & 12 \\
\hline Active & 0 & 46 & 6 & 52 \\
\hline New & 0 & 2 & 32 & 34 \\
\hline Total & 0 & 54 & 44 & 98 \\
\hline
\end{tabular}

Because this investigation does not go beyond the realms of case study, I cannot make any broad generalizations about O. Yet, as discussed in footnote 9 , pronouns have a strong tendency to refer to NPs in the immediately previous clause (=Active, in this study), and the number of pronouns has been increasing over history, as shown later. These two findings may support the diachronic transition of the $\mathrm{O}$ role; the pragmatic role of introducing new information may have been taken over to OBL, as shown in section 3.4. I will tentatively conclude here that, in English, pronouns frequently refer to NPs in the immediately previous clause, which enables the speaker/hearer or the writer/reader to easily perceive the information flow. ${ }^{10}$

\subsection{Diachronic Aspects of OBL in English}

Thompson (1997:75) argues that the pragmatic role of OBL is rarely Given, Identifiable, and Tracking. In her English conversational data, the ratios of Given information in core and oblique labels are: $89 \%$ in $\mathrm{A}, 65 \%$ in $\mathrm{S}$ and $\mathrm{O}$, and $35 \%$ in OBL (p.72). It is worth noting that new information is skewed in OBL in her data. The following are my findings about OBL.

(13) Findings about OBL based on 4 selected texts

a. OE through PDE, OBL has been preferred for the introduction of $(\mathrm{New} /) \mathrm{Lex}$.

b. In PDE, however, OBL comes to take (Act/)Pron though less preferable than (New/)Lex.

\footnotetext{
${ }^{10}$ As pointed out by Elizabeth Closs Traugott, pronouns function cataphorically as well as anaphorically in OE more often than not. Yet as shown in note 9, the proportional frequency of reference is anaphoric-oriented.
} 
(14) Proportional Frequency of Pronominal vs. Lexical Mentions in OBL

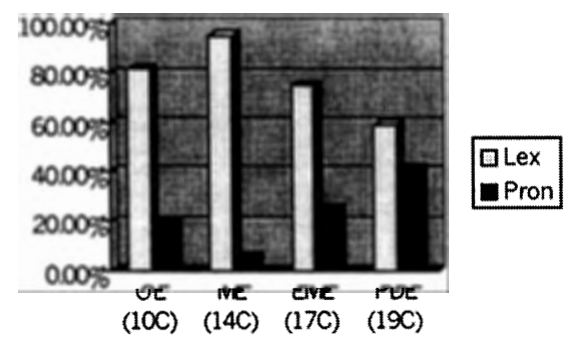

(15)

(a) OBL in OE (10C)

\begin{tabular}{|c|c|c|c|c|}
\hline & Null & Pron & Lex & Total \\
\hline Old & 0 & 8 & 42 & 50 \\
\hline Active & 0 & 12 & 6 & 18 \\
\hline New & 0 & 4 & 60 & 64 \\
\hline Total & 0 & 24 & 108 & 1.32 \\
\hline
\end{tabular}

(c) OBL in EModE (17C)

\begin{tabular}{|c|c|c|c|c|}
\hline & Null & Pron & Lex & Total \\
\hline Old & 0 & 4 & 4 & 8 \\
\hline Active & 0 & 12 & 0 & 12 \\
\hline New & 0 & 8 & 68 & 76 \\
\hline Total & 0 & 24 & 72 & 96 \\
\hline
\end{tabular}

(b) OBL in ME (14C)

\begin{tabular}{|c|c|c|c|c|}
\hline & Null & Pron & Lex & Total \\
\hline Old & 0 & 2 & 6 & 8 \\
\hline Active & 0 & 2 & 2 & 4 \\
\hline New & 0 & 0 & 68 & 68 \\
\hline Total & 0 & 4 & 76 & 80 \\
\hline
\end{tabular}

(d) OBL in PDE (19C)

\begin{tabular}{|c|c|c|c|c|}
\hline & Null & Pron & Lex & Total \\
\hline Old & 0 & 4 & 2 & 6 \\
\hline Active & 0 & 24 & 2 & 26 \\
\hline New & 0 & 4 & 42 & 46 \\
\hline Total & 0 & 32 & 46 & 78 \\
\hline
\end{tabular}

As shown in (14), the diachronic aspects of OBL may support the Thompson's findings for OBL. The important thing is, however, that in my data from ME on, OBL has been disfavoring the introduction of new information. Suppose that this tendency continues, the ratio of pronominal mentions in OBL would be dominant over that of lexical mentions. This speculation nicely leads to the findings in Kärkkäinen (1996:680ff). According to Kärkkäinen, OBL disfavors introducing new referents in (two of her) American conversational texts (the average ratio of lexical mentions is $22.3 \%$ in OBL). ${ }^{11}$ My texts do not provide us with such a dramatic picture; however, the findings from Kärkkäinen (1996), Thompson (1997), and this study suggest that in contrast to previous research, there is possibility that even OBL may be influenced by genres and types of discourse (Information Pressure).

${ }^{11}$ It is noteworthy that the ratio of lexical mentions in OBL $(22.3 \%)$ is less than that of O $(31.6 \%)$ in Kärkkäinen (1996:680). Yet pragmatic dimensions of her data show a clear continuum of new information skewing: $5.1 \%$ in $\mathrm{A}, 7.9 \%$ in $\mathrm{S}, 47.6 \%$ in $\mathrm{O}$, and $61.4 \%$ in OBL (ibid.:684). 


\section{Summary and Diachronic Implications}

We have thus far investigated the paths each category has traveled through time. These paths are complex in that the information status of each category varies from stage to stage; however, the diachronic transition of PAS is not random, but is motivated. Because of limitations of space, I cannot present all findings from this study, but I will focus on two important findings which go beyond the previous views of PAS both cross-linguistically and diachronically.

(16) Transition of Pronouns vs. Lexical Nouns in PAS (a case study)

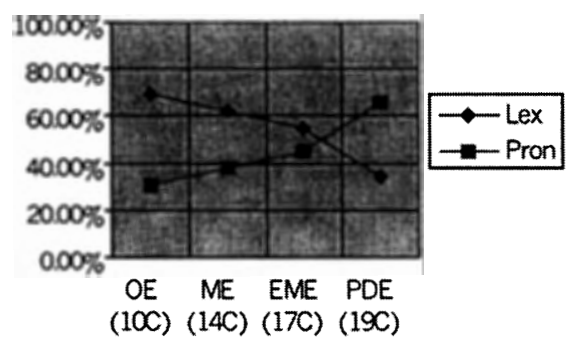

One is that all categories have come to favor pronominal mentions over history; in other words, both the number and proportional frequencies of pronouns have increased in all categories over history: 124/412 (30.1\%) in OE, 148/394 (37.6\%) in ME, 156/348 (44.8\%) in EModE, 276/422 (65.4\%) in PDE. These are summarized in (16). This study is just based on a kind of verse texts, not prose texts; therefore I will not generalize this diachronic transition to other genres. However, building on the findings from this study, I am led to conclude that information has come to be oriented toward the preceding discourse rather than the following discourse. Remember that as discussed in note 9, the most preferable position where pronouns refer to is the immediately previous clause. Thence, it can be considered that English has come to favor 1) lexically pronominal mentions and 2) pragmatically anaphoric functions. These are not absolute, but can be supported by the findings from this study.

The other important thing is that each category has grammaticalized the need to place the most appropriate information in it. As illustrated in section 3, each category shows its grammaticalized information status at each stage. They are summarized in (17). Note that the more to the left a category is, the less likely it is to be a lexical or new mention.

Transition of Implicational Hierarchy

\begin{tabular}{|c|c|c|}
\hline $\mathrm{A}(28.6 \%)<\mathrm{S}(50 \%)$ & $<\mathrm{OBL}(81.8 \%)<\mathrm{O}(88.1 \%)$ & $\mathrm{OE}(10 \mathrm{C})$ \\
$\mathrm{A}(17.8 \%)<\mathrm{S}(55.6 \%)<\mathrm{O}(81 \%)$ & $<\mathrm{OBL}(95 \%)$ & $\mathrm{ME}(14 \mathrm{C})$ \\
$\mathrm{A}(10 \%)<\mathrm{S}(43.9 \%)<\mathrm{O}(70.9 \%)$ & $<\mathrm{OBL}(75 \%)$ & $\mathrm{EME}(17 \mathrm{C})$ \\
$\mathrm{A}(8.2 \%)<\mathrm{S}(32.4 \%)<\mathrm{O}(44.9 \%)$ & $<\mathrm{OBL}(60 \%)$ & $\mathrm{PDE}(19 \mathrm{C})$ \\
\hline
\end{tabular}


Although the order of $\mathrm{O}$ and $\mathrm{OBL}$ in $\mathrm{OE}$ is reversed in $\mathrm{ME}$, the hierarchy: $\mathrm{A}<$ $\mathrm{S}<\mathrm{O}<\mathrm{OBL}$, based on the ratio of new and lexical information, seems to have been grammaticalized over history, at least after ME. This motivated hierarchy has diachronically moved in one direction, with the increasing number and proportional frequencies of pronouns, as in (16). All in all, information flow has been motivated grammatically and pragmatically in English, and diachronically as well.

\section{References}

Arnold, J. 1998. Reference form and discourse patterns. PhD dissertation, Stanford University.

Ashby, W. J. \& Bentivoglio, P. 1993. Preferred argument structure in spoken French and Spanish. Language Variation and Change 5: 61-76.

Ashby, W. J. \& Bentivoglio, P. to appear. Preferred argument structure across time and space. In Du Bois, J. W., Kumpf, L. \& Ashby, W. J. (eds.) Preferred argument structure. Amsterdam: John Benjamins.

Benson, L. D. et al. (eds.) 1987. The Riverside Chaucer. Oxford: Oxford UP.

Dixon, R. M. W. 1979. Ergativity. Language 55 (1): 59-138.

Du Bois, J. W. 1987. The discourse basis of ergativity. Language 63 (4): 805855.

Durie, M. 1988. Preferred argument structure in an active language. Lingua 74:1-25

Genetti, C. \& Crain, L. D. to appear. Beyond preferred argument structure:

Sentences, pronouns, and given referents in Nepali. In Du Bois, J. W., Kumpf, L. \& Ashby, W. J. (eds.) Preferred argument structure. Amsterdam: John Benjamins.

Gibson, R. (ed.) 1993. The Tempest. Cambridge: Cambridge UP.

Givón, Talmy. 1983. Topic continuity in discourse: an introduction. In T.

Givón, (ed.) Topic continuity in discourse. Amsterdam: John Benjamins.

Goffman, E. 1967. Interaction Ritual. Garden City, NY: Anchor Books.

Herring, S. 1989. Verbless presentation and the discourse basis of ergativity. Papers from the $25^{\text {th }}$ Annual Meting of the Chicago Linguistic Society, 123-137. Chicago: Chicago Linguistic Society.

Hiltunen, Risto. 1997. Aspects of The Battle of Maldon. A lecture/handout at the Rikkyo Seminar on English Philology, May 20, 1997, at the Dept. of English, Rikkyo (St. Paul) University, Tokyo, Japan.

Kärkkäinen, E. 1996. Preferred argument structure and subject role in American English conversational discourse. Journal of Pragmatics 25 (5): 675-701. 
Kumpf, L. 1993. Grammatical roles and participant introduction in native English and second language discourse. Ms., California State University, Long Beach.

Matsumoto, K. 2000. Intonation units, clause and preferred argument structure in conversational Japanese. Language Science 22: 63-86.

O'Dowd, E. 1990. Discourse pressure, genre and grammatical alignment after Du Bois. Studies in Language 14 (2): 365-403.

Raby, P. (ed.) 1995. The Importance of Being Earnest and Other Plays (by Oscar Wilde). Oxford: Oxford UP.

Robinson, F. C. 1976. Some aspects of the Maldon Poet's artistry. Journal of English and Germanic Philology 75: 25-40.

Scragg, D. G. (ed.) 1981. The Battle of Maldon. Manchester: Manchester UP.

Thompson, S. A. 1997. Discourse motivations for the core-oblique distinction as a language universal. In Akio Kamio (ed.) Directions in Functional Linguistics. Amsterdam: John Benjamins.

Reijirou Shibasaki

Department of Linguistics

University of California, Santa Barbara

Santa Barbara, California 93106-3100

U.S.A.

reijirou@umail.ucsb.edu 